\title{
Evaluation of the protein biomarkers and the analgesic response to systemic methylene blue in patients with refractory neuropathic pain: a double-blind, controlled study
}

\author{
This article was published in the following Dove Press journal: \\ Journal of Pain Research \\ 15 July 2015 \\ Number of times this article has been viewed
}

\section{Adriana A Miclescu' \\ Martin Svahn' \\ Torsten E Gordh ${ }^{1,2}$}

'Multidisciplinary Pain Clinic, Uppsala University Hospital, ${ }^{2}$ Pain Research, Department of Surgical Sciences, Uppsala University, Uppsala, Sweden
Correspondence: Adriana A Miclescu Multidisciplinary Pain Clinic, Uppsala University Hospital, SE-75I 85 Uppsala, Sweden Tel +46 I86 II 863

Email adriana.miclescu@surgsci.uu.se
Aim: This study was carried out in patients with neuropathic pain in order to assess the analgesic effects and changes in protein biomarkers after the administration of methylene blue (MB), a diaminophenothiazine with antioxidant and anti-inflammatory properties, and with inhibitory effects on nitric oxide.

Materials and methods: Ten patients with chronic refractory neuropathic pain were randomized to receive either MB (10 mg/mL Methylthioninium chloride) $2 \mathrm{mg} / \mathrm{kg}$ (MB group) or MB $0.02 \mathrm{mg} / \mathrm{kg}$ (control group) infused over 60 minutes. Sensory function and pain (Numerical Rating Scale) were evaluated at baseline and at 60 minutes after the start of the infusion. The patients kept a pain diary during the next 24 hours and for the following 4 days. Plasma and urinary concentrations of 8-isoprostane-prostaglandin F2 $\alpha$ (8-iso-PGF2 $\alpha$ ) and plasma protein biomarkers prior to and after the infusions were measured with radioimmunoassay and with proximity extension assay.

Results: A decrease of the Numerical Rating Scale at 60 minutes in comparison with baseline was observed in the MB $(P=0.047)$ group. The decrease was significant between the MB and the control group on the day of and day after MB infusion ( $P=0.04$ and $P=0.008$, respectively). There was no difference in systemic protein expressions between groups except for prolactin (PRL) $(P=0.02)$. Three patients demonstrated diminished dynamic mechanical allodynia.

Conclusion: MB decreased the pain levels in patients with chronic therapy-resistant neuropathic pain on the first 2 days after administration. Known as an endocrine modulator on the anterior pituitary gland, MB infusion produced a decrease of PRL. The detailed role of PRL effects in chronic neuropathic pain remains undetermined.

Keywords: methylene blue, nitric oxide, neuropathic pain

\section{Introduction}

Chronic pain patients show a significant increase in plasma levels of nitric oxide (NO) in comparison with healthy individuals. ${ }^{1}$ Therefore, the development of NO synthase (NOS) inhibitors may be regarded as a future therapy for patients with chronic pain syndromes. $\mathrm{N}^{\mathrm{G}}$-monomethyl-L-arginine hydrochlorides (L-NMMA) and methylene blue (MB) are the inhibitors of NOS, which have been tested thoroughly in humans beings. ${ }^{3-14}$ L-NMMA inhibits all three types of NOS (endothelial NOS, neuronal NOS, and inducible NOS). ${ }^{15}$ L-NMMA is effective in the treatment of chronic tension-type headache, ${ }^{3,4}$ and it was tested in neuropathic pain in humans. ${ }^{5} \mathrm{MB}$ has direct inhibitory effects on NOS, both constitutive and inducible, ${ }^{6,7}$ and it blocks the accumulation of cyclic guanosine monophosphate (cGMP) by inhibiting the enzyme guanylate cyclase. ${ }^{6}$ 
A valuable property of $\mathrm{MB}$ is its antioxidant effects. ${ }^{8}$ It inhibits the formation of free oxygen radicals and superoxides by competing with molecular oxygen for the transfer of electrons by xanthine oxidase. ${ }^{9}$

Previously, MB was used in different pain conditions with different routes of administration. Administrated intradiscally, MB attenuated chronic discogenic low back pain. ${ }^{10}$ Pretreatment with intravenous MB diminished the effective propofol dose during anesthesia ${ }^{11}$ and decreased the pain on injection with propofol. ${ }^{12}$ Perianal injection of MB administrated intradermally was useful in reducing postoperative pain after open hemorrhoidectomy and postoperative pain after sphincterotomy. ${ }^{13,14}$ The precise mechanisms of MB treatment implicated in these effects are not completely understood.

$\mathrm{MB}$ has great affinity for nervous tissue ${ }^{15}$ and has a remarkably high permeability through biomembranes due to a high lipophilicity. ${ }^{16}$ In animal models, the administration of MB induced antinociceptive effects in sciatic nerve ligated models of neuropathic pain. ${ }^{17}$ In chemically induced ischemia in rats, $\mathrm{MB}$ was demonstrated to play a dual role with a potent analgesic effect at lower doses, and a there was a dose-dependent reversal of the analgesic effect at higher doses. ${ }^{18}$ Based on these animal studies, there appears to be the potential for the application of MB in the treatment of patients suffering from neuropathic pain conditions.

The purpose of this study was to test the effects of MB in chronic refractory neuropathic pain. In order to discriminate between the different effects of $\mathrm{MB}$, we applied a proximity extension assay (PEA) technique to identify potentially serological proteins biomarkers and radioimmunoassay (RIA) to identify the possible antioxidants effects of MB.

\section{Materials and methods}

This randomized, double-blind study was performed in accordance with the ethical principles for medical research involving human subjects that have their origin in the updated Declaration of Helsinki, and it was approved by the Regional Ethics Committee and included in the European Union Clinical Trials Register 2008-005783-14 and clinical trials NCT02303886. The study was carried out at the Multidisciplinary Pain Center at Uppsala University Hospital, Uppsala, Sweden.

\section{Patients}

Ten study participants were screened from a pool of patients with chronic therapy-resistant neuropathic pain (more than 12 months and up to a maximum of 5 years), and they were eligible to participate in the study after giving written informed consent (Table 1). Chronic refractory neuropathic pain was considered when patients have had "a trial of treatment with at least four drugs of known effectiveness in neuropathic pain, tried for at least 3 months or until adverse effects prevent adequate dosage, with no effect on the intensity of pain". ${ }^{19}$ Where indicated, the patients had tried nonpharmacological treatments such as spinal cord stimulation and multidisciplinary pain programs with no effect on the intensity of pain.

\section{Study design}

The patients visited the pain clinic twice. The interval between the treatments was, in most cases, 2 weeks. Oral and written information about the study was provided and informed consent was obtained. Demographic data (date of birth, sex, and ethnic background, as well as medical and surgical history)

Table I Inclusion and exclusion criteria

\begin{tabular}{|c|c|}
\hline Number & Inclusion criteria \\
\hline I & Female or male subjects $>18$ years of age. \\
\hline 2 & $\begin{array}{l}\text { Ability to understand and comply with the requirements } \\
\text { of the study. }\end{array}$ \\
\hline 3 & $\begin{array}{l}\text { Patients with a history of chronic peripheral and central } \\
\text { neuropathic pain of more than } 12 \text { months and up to } \\
\text { a maximum of } 5 \text { years' duration interfering with daily } \\
\text { activities. }\end{array}$ \\
\hline 4 & $\begin{array}{l}\text { Patients with previously unsuccessful treatments for } \\
\text { neuropathic pain: pharmacological treatments with more } \\
\text { than four drugs tried for more than } 3 \text { months, or until } \\
\text { side effects developed; and those associated (or not) } \\
\text { with nonpharmacological pain treatment, such as spinal } \\
\text { cord stimulation and multidisciplinary pain treatment. }\end{array}$ \\
\hline 5 & $\begin{array}{l}\text { Spontaneous or evoked pain upon standardized testing } \\
\text { (mechanical, movement) ( }>5 \text { points on a I0-point } \\
\text { Numerical Rating Scale). }\end{array}$ \\
\hline 6 & Informed written consent. \\
\hline Number & Exclusion criteria \\
\hline I & $\begin{array}{l}\text { Any condition that may confound the assessment of pain } \\
\text { (acute pain). }\end{array}$ \\
\hline 2 & $\begin{array}{l}\text { Any condition/disease that could interfere with the } \\
\text { study measurements - eg, peripheral vascular disease, } \\
\text { diabetes mellitus, alcohol/opioid addiction. }\end{array}$ \\
\hline 3 & Noncooperation, insufficient Swedish-language. \\
\hline 4 & $\begin{array}{l}\text { Treatment with antidepressants, antiepileptics, opioids, } \\
\text { or lidocaine patches was not allowed the day before and } \\
\text { the day of the visit. }\end{array}$ \\
\hline 5 & Pregnancy. \\
\hline 6 & $\begin{array}{l}\text { Treatment with nitric oxide-releasing drugs or } \\
\text { anticytokine therapy. }\end{array}$ \\
\hline 7 & $\begin{array}{l}\text { Diabetes mellitus type I, malignancy, increased } \\
\text { pulmonary hypertension, cardiac ischemic disease, } \\
\text { a decreased glomerular filtration rate }<30 \mathrm{~mL} / \mathrm{min} \text {, } \\
\text { decreased liver function, or glucose-6-phosphate } \\
\text { dehydrogenase deficiency. }\end{array}$ \\
\hline
\end{tabular}


were recorded. Information about the patients' assessments was recorded before the injection, including current medication and other (successful or unsuccessful) treatment attempts (Table 2). Depression and anxiety were evaluated according to the Hospital Anxiety and Depression Scale (HADS). The same investigator (AAM) performed all study procedures and examinations. Assessments of sensory function were performed before drug administration.

\section{Administration of study drug}

Ten patients were randomized by a computer-generated random list to receive either MB $2 \mathrm{mg} / \mathrm{kg}(10 \mathrm{mg} / \mathrm{mL}$ methyltioninklorid; Apoteket, Umeå, Sweden) or MB $0.02 \mathrm{mg} / \mathrm{kg}$ (that served as the control) added to $5 \%$ glucose. The same volume of $5 \%$ glucose $(250 \mathrm{~mL})$ was infused intravenously over 60 minutes. After monitors for electrocardiography (ECG), noninvasive arterial blood pressure (BP), and pulse oximetry were placed, a 20-gauge cannula was inserted into the dorsum of the nondominant hand for administration of the study drugs. Pain was measured at baseline and at 60 minutes after the start of the infusion (Numerical Rating Scale [NRS]), and also with a pain diary during the next 24 hours and in the following 5 days. ECG, pulse, BP, and $\mathrm{O}_{2}$ saturation were continuously recorded during the infusion. Blood and urine samples were taken before and after the infusion of MB. Neither the subjects nor the person examining the patients knew the concentration of $\mathrm{MB}$ in the infusion. The infusions of $\mathrm{MB}$ in 5\% glucose were prepared by another person who had access to the randomization list, but who was not involved in monitoring the patients. The infusions bags were covered in opaque red wraps and the infusions sets were opaque.

\section{Pain assessments}

The duration of the present pain condition was recorded. The assessments were performed under the same conditions - ie, at the same place and time of day. The primary endpoint measure was defined as the change in pain score measured from baseline until 60 minutes after infusion. Assessments of pain were performed in the following order: spontaneous pain; assessment of dynamic mechanical allodynia; and pinprick hyperalgesia.

Ongoing pain was the pain felt by the patients in the affected area (without an apparent external cause) and was projected to the innervation territory of the injured nerve. The perception of pain was assessed using an NRS with responses ranging from 1 to 10 , where $0=$ no pain and $10=$ worst imaginable pain. The evaluation of sensory function was performed using a bedside examination according to the European Federation of Neurological Societies guidelines; light touch, pinprick sense, as well as warm $\left(40^{\circ}\right)$ and cold $\left(25^{\circ}\right)$ temperature stimuli were tested. ${ }^{20,21}$ The patient compared the sensations from the site of injury with those from the contralateral uninjured side and reported if there was any hypoesthesia, hyperesthesia, allodynia, or simply normal sensations to the different stimuli. The pain recordings were determined before and after infusion of MB. Patients kept a diary where they could indicate their pain levels on a scale between 0 and 10 (NRS) every 6 hours after the infusion for the first 24 hours, and then every 8 hours thereafter for the next 5 days.

\section{Sensory testing}

Dynamic mechanical allodynia (light touch) was assessed with a camel hair brush ( 0.5 ; SOMEDIC AB, Hörby, Sweden) by stroking in eight compass-point directions with a speed of $1 \mathrm{~cm} / \mathrm{sec}$, starting peripherally and moving to the center of the projection territory of the injured nerve. The patient, eyes closed, stated when the stimulus changed to a more painful condition. The border of the allodynic area was marked before and after the examination with a pen before and after the infusion. Punctate hyperalgesia (pinprick sense) was tested using a sharp cocktail pin. Cold and warm allodynia detection were determined using suprathreshold stimuli inside the affected skin area and in the contralateral corresponding nonpainful area using metallic rollers (Lindblom rollers) preheated to $40^{\circ} \mathrm{C}$ or precooled to $25^{\circ} \mathrm{C}$ (SENSELab Rolltemp; SOMEDIC AB).

\section{Analytical methods}

Peripheral venous blood was drawn from the fasting subjects using a 19-gauge needle. Urine was collected into additivefree tubes. Plasma was prepared from blood collected in tubes containing heparin by centrifugation $(3,500 \times g$ for 12 minutes). Urine and plasma samples were stored at $-70^{\circ} \mathrm{C}$ until analysis. Blood and urine samples were collected before and after the infusion of MB.

\section{Plasma and urine concentrations of isoprostane 8-iso-PGF2 $\alpha$}

Plasma and urine concentrations of isoprostane 8-isoprostaglandin (PG)F2 $\alpha$ (an indicator of oxidative injury), were measured according to a highly specific and validated RIA method in our laboratory, as previously described. ${ }^{22}$ The detection limit for 8-iso-PGF2 $\alpha$ was $23 \mathrm{pmol} / \mathrm{L}$. Normal values are $<50 \mathrm{pg} / \mathrm{mL}$ in plasma and $<0.9 \mathrm{nMol} / \mathrm{L}$ in urine. ${ }^{22}$ 


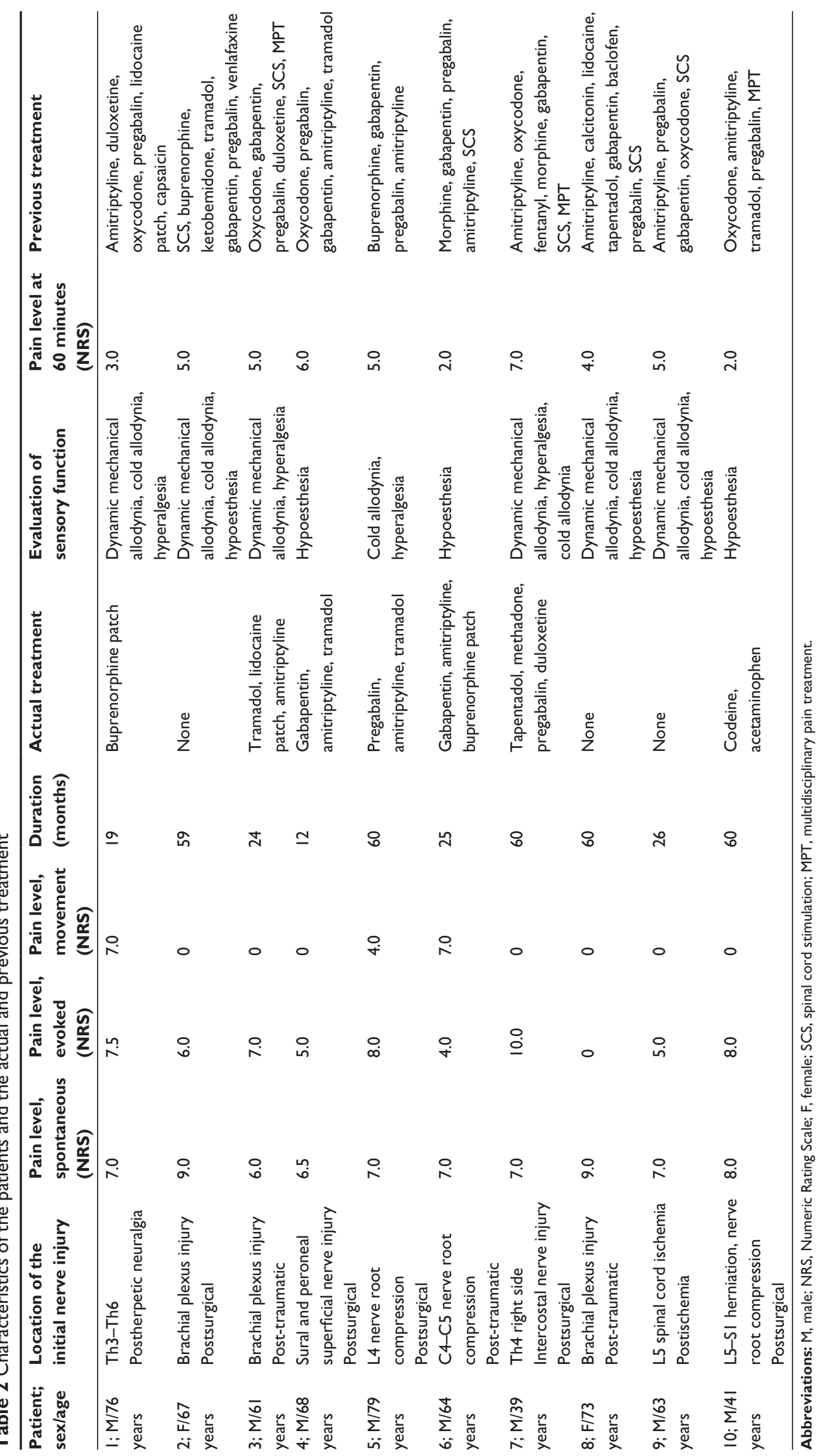




\section{Proximity extension assay}

PEA has been found to have specificity of detection and analysis of an increased range of target molecules. PEA technology consisted of a panel of 92 oligonucleotide labeled antibody probe pairs (Proseek assay kit) that bind to their respective targets present in the sample. Protein targets can be readily detected and localized with single molecule resolution and objectively quantified. When binding to their correct targets, they give rise to new DNA polymerase, forming a new sequence that now acts as a unique surrogate marker for the specific antigen. This sequence is then quantified by quantitative real-time polymerase chain reaction, where the number of polymerase chain reaction templates formed is proportional to the initial concentration of antigen in the sample..$^{23-25}$ The assay was performed according to Proseek's standard protocol (Proseek Multiplex Oncology; Olink Bioscience, Uppsala, Sweden).

\section{Statistics}

Nonparametric statistical methods were performed by the author using GraphPad PRISM 5.0 (GraphPad Software, Inc., La Jolla, CA, USA www.graphpad.com 5.0). Data are presented as the mean and standard deviation with $95 \%$ confidence intervals. The level of significance was set at a $P$-value $<0.05$. The sample size calculation was based on a sample size calculation of analgesia from a previous study (number $[\mathrm{n}]=10$ ). ${ }^{11}$ Variability data for the analgesic effects of MB required for a formal power calculation were not available. For comparisons of single time points for pain intensity testing between the groups, the Kruskall-Wallis test was used. Further, pairwise analyses for nonparametric variables were performed by the Mann-Whitney $U$-test, where differences between the groups were evident. The differences between the two treatments from baseline to the end of the study were compared with two-way repeated measures analysis of variance. Samples of plasma and urine were run blind, so that previous proteomic results were unknown. For each data point of PEA, the raw Cq-value ( $\log _{2}$ scale) was normalized. The resulting delta $\mathrm{Cq}(\mathrm{dCq})$ value was compared to that of the corresponding background reaction. The result was expressed either in a $\log _{2}$ scale or as linearized values. ${ }^{25}$ For a comparison between the protein concentrations, the paired $t$-test was used in the same group before and after administration of the infused solutions. For comparison between the groups, the unpaired $t$-test was used.

\section{Results}

All the patients completed the study. Table 2 shows the demographic and clinical characteristics of the patients.

\section{Pain assessments}

Ongoing pain was reported in all patients. A decrease of more than $30 \%$ of the NRS in comparison with baseline was observed in the MB group $(P=0.047)$ immediately after the infusion, at 6 hours after baseline, and at 10 hours, 14 hours, and 18 hours $(P<0.01)$. The same magnitude in the decrease of the NRS continued throughout the second day. Statistically significantly lower NRS scores in the MB group, in comparison with the control group, were observed on the day of the infusion $(P=0.04)$ and on the second day $(P=0.008)$ (Figure 1). The placebo effect at 60 minutes was relatively large, although it did not reach statistical significance. Two patients in the control group and seven patients in the MB group reported in their pain diaries a subjective improvement after infusions. Anecdotally, one patient returned to the clinic in order to receive subsequent infusions after the study ended.

\section{Dynamic mechanical allodynia}

Six patients reported dynamic mechanical allodynia in both sessions. The area of dynamic mechanical allodynia decreased after the administration of MB in three patients (patient 1 with postherpetic neuralgia; patient 3 with post-traumatic brachial plexus injury; and patient 9 with central neuropathic pain after L5 spinal ischemia) (Figure 2). Cold allodynia was present in six out of ten patients. Punctate hyperalgesia was found in four out of ten patients, and hypoesthesia in six out of ten patients. These were unchanged postinfusion.

\section{Blood pressure, pulse, saturation}

No differences in BP, pulse, or saturation (Figure 3) were registered between the groups and in the same group before and after the administration of MB $(P>0.05)$.

\section{Depression}

Depression, as evaluated with the HADS (score over 8), was present in four patients, and anxiety was present in two patients.

\section{Adverse reaction}

During the infusion, the most common adverse reaction was pain at the site of infusion and in the infused arm in four of ten patients (moderate in three patients and severe in one patient in the MB group). The most commonly occurring adverse reactions (Table 3 ) after the infusion were abdominal pain (two patients) and nausea (two patients). The frequency of these reactions was higher in the MB group than in the control group. 


\section{Numerical rating scale}

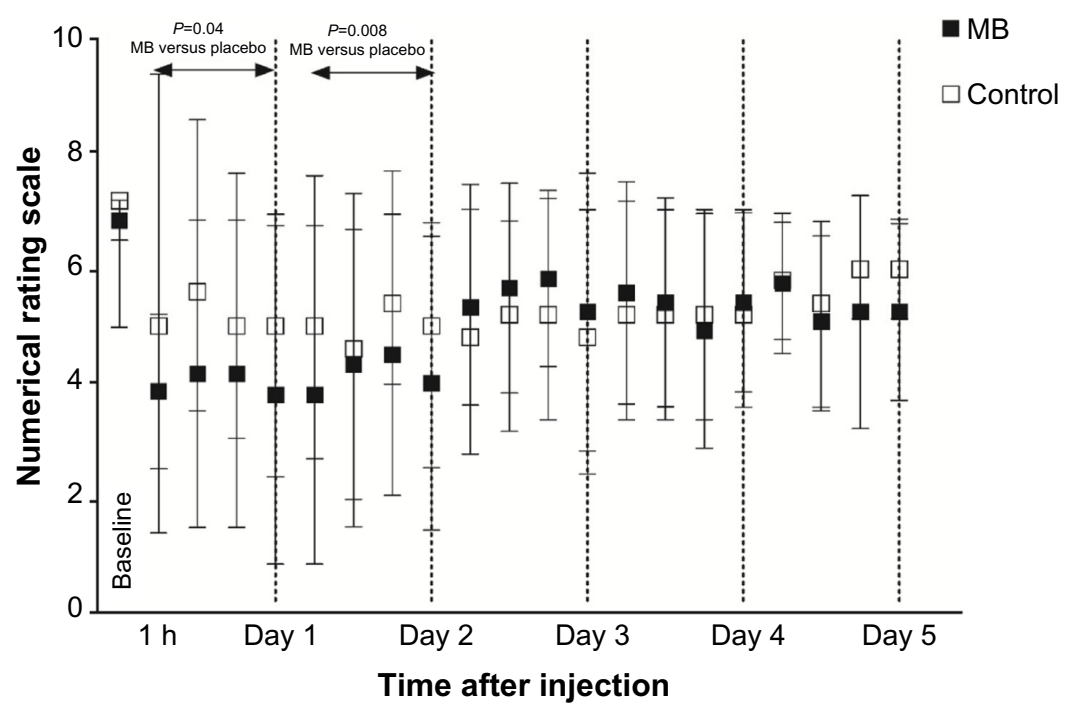

Figure I Numerical Rating Scale before and after the administration of MB (black) and in the control group (white).

Note: The values are presented as the mean and $95 \%$ confidence intervals.

Abbreviations: $M B$, methylene blue; $h$, hour.

\section{Levels of 8-iso-PGF2 $\alpha$}

No significant differences were seen between groups in the levels of 8-iso-PGF2 $\alpha(P>0.05)$. At baseline, no patients had signs of oxidative stress, as indicated by increased levels of 8 -iso-PGF $2 \alpha$. The mean levels of 8 -iso-PGF $2 \alpha$ in the blood at baseline were as follows: in blood, $45 \mathrm{pg} / \mathrm{mL}$, and in urine, $0.2 \mathrm{nMmol} / \mathrm{L}$ in the $\mathrm{MB}$ group; and $44 \mathrm{pg} / \mathrm{mL}$ in blood and $0.3 \mathrm{nMol} / \mathrm{L}$ in urine in the control group. After the infusions, the mean levels of 8-iso-PGF2 $\alpha$ were as follows: $34 \mathrm{pg} / \mathrm{mL}$ (MB group) and $44 \mathrm{pg} / \mathrm{mL}$ (control group) in blood; and $0.1 \mathrm{nMol} / \mathrm{L}$ (MB group) and $0.18 \mathrm{nMol} / \mathrm{L}$ (control group) in urine. The normal values were $<50 \mathrm{pg} / \mathrm{mL}$ in plasma and $<0.9 \mathrm{nMol} / \mathrm{L}$ in urine.

\section{PEA analysis}

There was no clear clustering of the treatment groups, as indicated by the dynamic PEA between the MB and control groups (significance level of $P=0.3$ ) (Figure 4). Perhaps some clustering existed in the dynamic PEA when comparing before treatment with after treatment in the MB and control groups (significance level of $P=0.4$ ) (Figure 5). The data can be used for relative quantification between samples, or groups of samples, but the data do not give absolute protein concentrations. Both in the MB and in the control groups, significantly lower serum concentrations of prolactin (PRL) in comparison with baseline were observed after the infusion ( $P=0.006$ and $P=0.009$, respectively) (Table 4). Levels of PRL were different between groups $(P=0.02)$. There were significantly higher concentrations of CD40 ligand, caspase 3, growth hormone, and interleukin (IL)-6 after treatment with $\mathrm{MB}$ in several patients, as follows: CD40 ligand, patients 1 and 4; caspase 3, patients 1 and 3; growth hormone, patients 2, 3, 5, 6, and 7; and IL-6 in patients 1 , 2, and 3. Lower concentrations after MB administrations

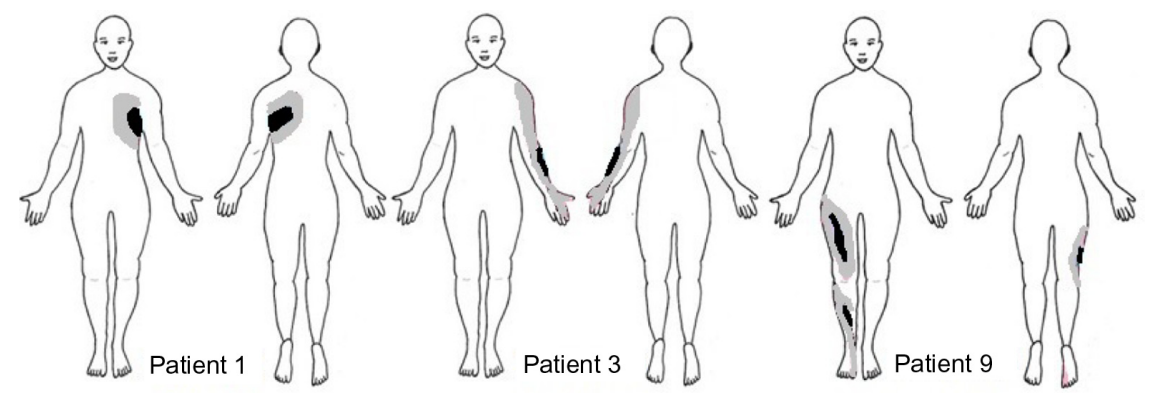

Figure 2 Area of mechanical allodynia before MB (gray) and after MB (black) in patients I (postherpetic neuralgia), 3 (post-traumatic brachial injury), and 9 (central neuropathic pain after spinal cord ischemia).

Abbreviation: MB, methylene blue. 


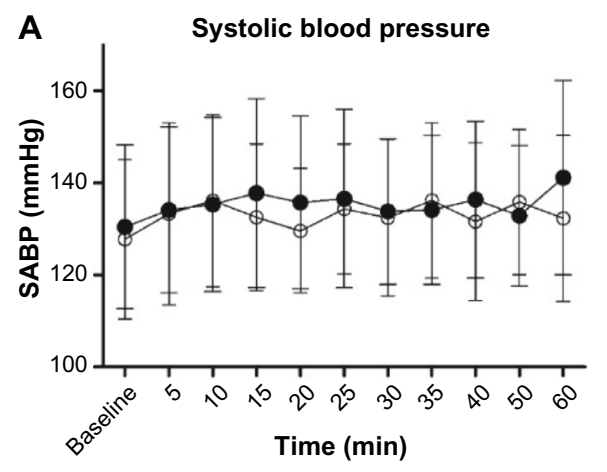

B

Oxygen saturation

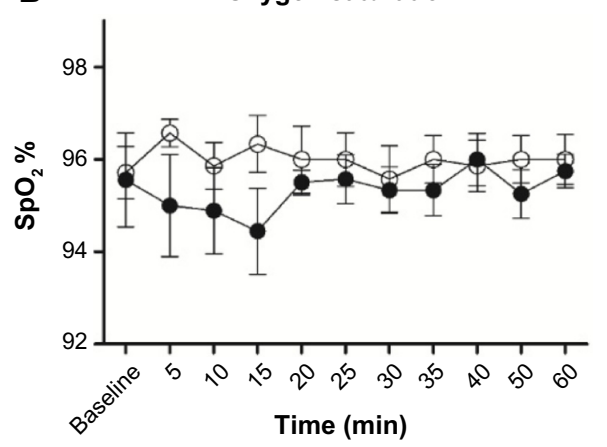

$-\mathrm{MB}$

- Control

$P>0.05$

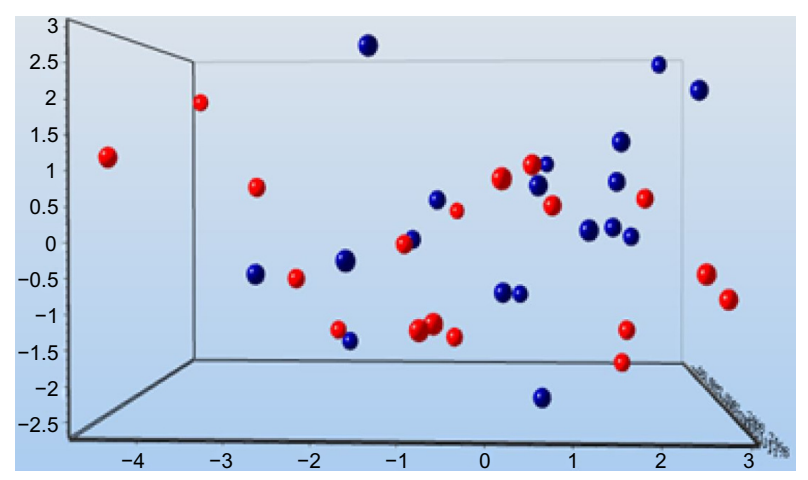

Figure 4 Principal component analysis comparing methylene blue (blue circles) with the control group (red circles).

Notes: There is no clear clustering between the treatment groups. Ten proteins that contributed to the PCA were selected of 87 proteins (prolactin, TGF- $\alpha$, TNF-RI, growth hormone, midkine, kallikrein-6, GM-CSF, cystatin B, CD69, and adrenomedullin). The significance level was $P=0.3$.

Abbreviations: PCA, principal component analysis; TGF, transforming growth factor; TNF, tumor necrosis factor; GM-CSF, granulocyte macrophage colonystimulating factor.

\section{Discussion}

\section{$M B$ and analgesia in neuropathic pain}

MB intravenous administration was associated with a more than $30 \%$ reduction of ongoing pain. The current study was based on the hypothesis that chronic neuropathic pain may be alleviated by MB through its properties as an NO inhibitor and antioxidant. As the mechanisms of neuropathic pain can involve the activation of NO- and cGMP-dependent signaling pathways in the spinal cord, ${ }^{26}$ one may speculate that the inhibition of this pathway by MB was the mechanism implicated

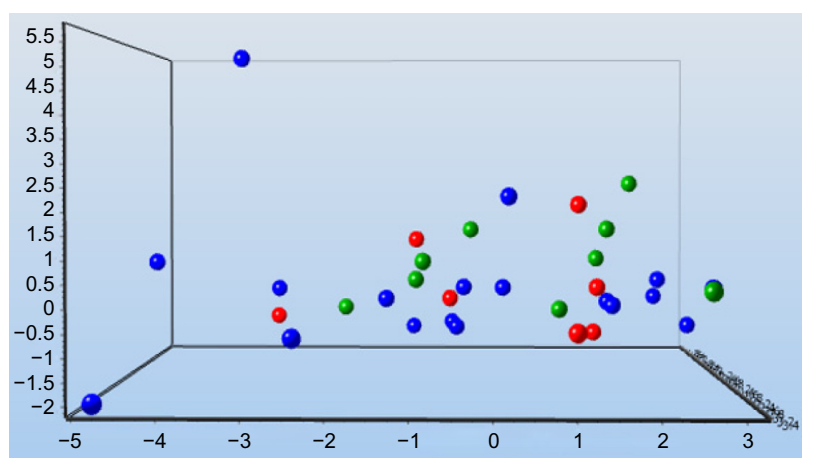
affected arm, more pain Dizziness, headache

No complications

Pain in the infusion arm, tired

No complications

No complications

No complications

No complications

Figure 5 Principal component analysis somparing the before treatment proteins (green circles) with after treatment proteins in the methylene blue group (blue circles) and control group (red circles).

Notes: There is some clustering observed before and after treatment. Fourteen proteins that contributed to the PCA were selected of 87 proteins (prolactin, TGF- $\alpha$, TNF-RI, growth hormone, kallikrein-6, GM-CSF, CD30-L, thrombopoietin, prostasin, MMP-3, CXCL-II, EMMPRIN, HE4, and IFN- $\gamma$ ). The significance level was $P=0.4$.

Abbreviations: PCA, principal component analysis. TGF, transforming growth factor; TNF, tumor necrosis factor; GM-CSF, granulocyte macrophage colonystimulating factor; MMP, matrix metalloproteinase; $\mathrm{CXCL},(\mathrm{C}-\mathrm{X}-\mathrm{C})$ motif ligand; IFN, interferon. 
Table 4 Proximity extension assay analysis

\begin{tabular}{|c|c|c|c|c|}
\hline Mediator class & Example & $\begin{array}{l}\text { Paired } t \text {-test before } \\
\text { and after methylene } \\
\text { blue ( } P \text {-value })\end{array}$ & $\begin{array}{l}\text { Paired } t \text {-test } \\
\text { before and after } \\
\text { control ( } P \text {-value })\end{array}$ & $\begin{array}{l}\text { Unpaired } t \text {-test between } \\
\text { the methylene blue and } \\
\text { control groups ( } P \text {-value) }\end{array}$ \\
\hline Cytokines & IL-I ra & 0.17 & 0.47 & 0.99 \\
\hline \multirow[t]{6}{*}{ IL } & IL-6 & 0.90 & 0.37 & 0.91 \\
\hline & IL-8 & 0.87 & 0.30 & 0.45 \\
\hline & IL-2ra & 0.98 & 0.42 & 0.65 \\
\hline & IL-6ra & 0.93 & 0.61 & 0.89 \\
\hline & IL-7 & 0.83 & 0.88 & 0.93 \\
\hline & $\mathrm{IL}-12$ & 0.77 & 0.42 & 0.84 \\
\hline TNF & TNF- $\alpha$ & 0.34 & 0.92 & 0.12 \\
\hline Hematopoietins & CSFI & 0.91 & 0.65 & 0.62 \\
\hline \multirow[t]{2}{*}{ IFN } & EPO & 0.14 & 0.96 & 0.91 \\
\hline & IFN-gamma & 0.74 & 0.09 & 0.54 \\
\hline Chemokines & CCL-19 & 0.93 & 0.62 & 0.74 \\
\hline \multirow[t]{2}{*}{ CC-chemokines } & CCL-2I & 0.84 & 0.68 & 0.64 \\
\hline & CCL-24 & 0.87 & 0.55 & 0.90 \\
\hline \multirow[t]{5}{*}{ CXC-chemokines } & CX3CL5 & 0.60 & 0.88 & 0.92 \\
\hline & CXCL9 & 0.85 & 0.63 & 0.39 \\
\hline & CXCLIO & 0.70 & $0.4 I$ & 0.40 \\
\hline & CXCLII & 0.15 & 0.63 & 0.67 \\
\hline & CXCLI3 & 0.50 & 0.62 & 0.90 \\
\hline \multirow[t]{2}{*}{ Proteolytic enzymes } & MMP-3 & 0.98 & 0.63 & 0.67 \\
\hline & Cathepsin D & 0.91 & 0.81 & 0.71 \\
\hline \multirow[t]{4}{*}{ Growth factors } & Adrenomedullin & 0.27 & 0.21 & 0.35 \\
\hline & EGF & 0.76 & 0.71 & 0.71 \\
\hline & EGFR & 0.97 & 0.27 & 0.74 \\
\hline & Betacellulin & 0.07 & 0.91 & 0.54 \\
\hline \multirow[t]{2}{*}{ Hormones } & Prolactin & 0.006 & 0.009 & 0.02 \\
\hline & Growth hormone & 0.092 & 0.87 & 0.31 \\
\hline
\end{tabular}

Note: The bold values indicate statistically significant values.

Abbreviations: IL, interleukin; TNF, tumor necrosis factor; CSFI, macrophage colony-stimulating factor; IFN, interferon; EPO, Erytropoetin; CCL, C-C motif chemokine: ligand; CXCL, Chemokine (C-X-C motif) ligand; MMP, matrix metalloproteinase; EGF, epidermal growth factor; EGFR, epidermal growth factor receptor.

in pain reduction. As the baseline values of 8 -isoPG $2 \alpha$, a marker of oxidative injury, were within the normal range in both plasma and urine in all patients, we could demonstrate that the antioxidant mechanism was responsible for the analgesic effects of MB.

In comparison with baseline, the pain levels registered by the patients on the same day and on the following day after the infusion of $\mathrm{MB}$ were lower. Although $\mathrm{MB}$ reaches its maximum concentrastion 5 minutes after intravenous administration, the exact mechanism underlying this effect is difficult to explain knowing that the intravenous administration of $\mathrm{MB}$ demonstrates a terminal plasma half-life of approximately 5-6 hours. ${ }^{27}$ Four patients had increased scores for depression. It is known that MB is a cationic phenothiazine derivative with diverse medical applications, such as in antidepressants and anxiolytics, ${ }^{28}$ but these effects appear after administration for a longer period (3 weeks for depression). ${ }^{29}$

A relatively strong effect was observed in the control group in relation to the reduction of analgesia (20\%). This is in accordance with a previous study that indicated a strong placebo response in neuropathic pain trials, which was higher in peripheral neuropathic pain $(23 \%)$ than central neuropathic pain (14\%), postherpetic neuralgia (19\%) and post-traumatic neuropathic pain $(15 \%) .{ }^{30}$ The urine turns blue after MB administration, which makes the drug difficult to test in traditional placebo-controlled clinical studies. Therefore, a low dose of MB, and not clear fluids, was used in the control group.

\section{$M B$ and dynamic mechanical allodynia}

Three of the six patients with dynamic mechanical allodynia demonstrated a decrease in the area of tactile allodynia. This observation may be explained hypothetically by the antinociceptive effects of MB on the N-methyl-D-aspartate (NMDA) receptors located in the dorsal spinal cord. Allodynia is produced by postsynaptic changes of second-order nociceptive neurons, such as phosphorylation of NMDA receptors in the spinal cord dorsal horn. ${ }^{31}$ The neuronal hyperexcitability enables 
low-threshold mechanosensitive $\mathrm{A} \beta$ - and $\mathrm{A} \delta$-afferent fibers to activate central pain pathways. ${ }^{31}$ Activation of NMDA receptors increases calcium conductance and activates the enzyme NOS, ultimately leading to NO synthesis and NO formation, which plays an important role in the development of allodynia. As $\mathrm{MB}$ is an inhibitor of soluble guanylate cyclase and $\mathrm{NO},{ }^{17,18}$ administration of a NO antagonist may reduce allodynia, ${ }^{32}$ and it may be considered responsible for these effects.

\section{$\mathrm{MB}$ and cytokine-chemokine networks}

Although cytokine-chemokine networks play a central role in the pathogenesis of neuropathic pain following nerve damage, ${ }^{33,34}$ no difference in cytokine and chemokine levels were observed between groups and in the same group after treatment. In a limited number of patients, some effects on CD40 (costimulatory protein), IL-6, and CXCL-11 were observed, but further efforts are needed to elucidate these effects. The lack of results is probably related to the time frame of collecting the blood samples. Also, this study did not compare the presence of these proteins in patients with neuropathic pain versus patients without pain.

\section{$M B$ and $P R L$}

Known as an endocrine modulator on the hypothalamopituitary-peripheral axis, ${ }^{35} \mathrm{MB}$ infusion influenced the production of PRL in both groups and, in some patients, the production of growth hormone. The endocrine abnormalities due to direct actions of opioids at the hypothalamic-pituitary level are recognized in the prolonged use of opioids, ${ }^{36}$ but very little is known about the release of this hormone after the administration of $\mathrm{MB} \cdot{ }^{37,38} \mathrm{PRL}$ is a small peptide hormone secreted by the anterior pituitary gland, as enhanced by stimulation of the serotonergic pathways. ${ }^{39}$ An animal study has demonstrated that MB alone did not change blood PRL concentrations, ${ }^{40}$ but with simultaneous estradiol treatment, anterior pituitary PRL levels decreased compared to controls. ${ }^{41}$ The effects observed for PRL appeared in both groups, with more effects found for PRL in the control group, attributed to the hormetic behavior of $\mathrm{MB}$; this was characterized by a maximal effect at a low dose range, followed by a decreasing effect at intermediate or high doses. ${ }^{42}$ Although it is known that PRL induced the sensitization of capsaicinevoked responses, as well as increased the phosphorylation of the transient receptor potential cation channel subfamily V member (TRPV1) in the trigeminal sensory neurons, ${ }^{43}$ the detailed role of PRL effects in the cellular mechanisms related to chronic neuropathic pain remain to be studied.

\section{$M B$ dose and adverse effects}

Glucose was used instead of sodium chloride because MB precipitates in sodium chloride solutions. ${ }^{44}$ There are no data in the literature about the dose of MB administrated in neuropathic pain, but the generally accepted therapeutic bolus dose of $\mathrm{MB}$ is $2 \mathrm{mg} / \mathrm{kg}^{45,46}$ administrated over 1 hour. $^{47}$

Eight of the ten patients in the MB group reported adverse effects comparable to those previously reported following MB administration: abdominal pain and nausea. Additionally, four of ten patients in the control group experienced adverse effects following infusion. Although it is considered to be safe, a case report has revealed adverse effects such as hyperpyrexia and postoperative disorientation after MB administration. ${ }^{48}$ Dose-related side effects (over $7 \mathrm{mg} / \mathrm{kg}$ ), such as nausea and vomiting, abdominal pain, and methemoglobinemia, are also described. ${ }^{46}$ Most of these side effects may be attributed to a chemical impurity of MB. Pharmaceutical MB may contain impurities, such as arsenic, aluminum, cadmium, mercury, and lead. ${ }^{16}$ At low doses, the presence of contaminants is not of great concern, but at higher doses, nonspecific effects due to the accumulation of various toxic and bioactive substances are possible. Thus, in future human studies, it is recommended to use purified MB.

Although MB may be effective in improving systemic hemodynamics in the setting of vasoplegia related to cardiac arrest, ${ }^{49}$ sepsis, ${ }^{50}$ and anaphylaxis, ${ }^{51}$ no effect on BP was observed in any patient, and there were no falsely low oxygen saturation readings.

\section{Limitations of the study}

Several limitations should be considered when interpreting the clinical effects of MB. Firstly, this was a pilot study with a low number of participants to test the efficacy of $\mathrm{MB}$ in neuropathic pain. As it was a limited study where the patients had different types of neuropathic pain, the results cannot be generalized to all patients with neuropathic pain. Secondly, patients with chronic refractory neuropathic pain would have a positive attitude to a new treatment, which may be considered a potential source of bias. Third, the NO concentration measurements in plasma were not measured. Due to its short half-life of a few seconds, it was very unstable in the blood; therefore, the results of the NO concentration could not be obtained by PEA.

\section{Conclusion}

As neuropathic pain responds poorly to the available pharmacological and interventional methods of treatment, this 
study represents a new approach for targeting neuropathic pain resistant to all conventional treatments.

\section{Acknowledgment}

We thank Stephen Butler, Rolf Karlsten, Samar Basu, Charlotte Ersson, and Bitte Hägneförs for their support in the study.

\section{Disclosure}

The authors report no conflicts of interest in this work.

\section{References}

1. Koch A, Zacharowski K, Boehm O, et al. Nitric oxide and proinflammatory cytokines correlate with pain intensity in chronic pain patients. Inflamm Res. 2007;56(1):32-37.

2. Ashina M, Bendtsen L, Jensen R, Olesen J. Nitric oxide-induced headache in patients with chronic tension-type headache. Brain. 2000;123 (Pt 9):1830-1837.

3. Ashina M, Lassen LH, Bendtsen L, Jensen R, Olesen J. Effect of inhibition of nitric oxide synthase on chronic tension-type headache: a randomised crossover trial. Lancet. 1999;353(9149):287-289.

4. Gordh T, Blomberg H. The effects of intravenous L-NMMA, a NOS inhibitor, in the treatment of patients with neuropathic pain. A double blind, placebo-controlled, cross over study. Poster presented at: Svenska Läkaresällskapets Riksstämma; 24-26 November; 2004; Stockholm.

5. Mayer B, Brunner F, Schmidt K. Inhibition of nitric oxide synthesis by methylene blue. Biochem Pharmacol. 1993;45(2):367-374.

6. Mayer B, Brunner F, Schmidt K. Novel actions of methylene blue. Eur Heart J. 1993;14 Suppl I:22-26.

7. Ohlow MJ, Moosmann B. Phenothiazine: the seven lives of pharmacology's first lead structure. Drug Discov Today. 2011;16(3-4):119-131.

8. Salaris SC, Babbs CF, Voorhees WD 3rd. Methylene blue as an inhibitor of superoxide generation by xanthine oxidase. A potential new drug for the attenuation of ischemia/reperfusion injury. Biochem Pharmacol. 1991;42(3):499-506.

9. Peng B, Pang X, Wu Y, Zhao C, Song X. A randomized placebocontrolled trial of intradiscal methylene blue injection for the treatment of chronic discogenic low back pain. Pain. 2010;149(1): 124-129.

10. Licker M, Diaper J, Robert J, Ellenberger C. Effects of methylene blue on propofol requirement during anaesthesia induction and surgery. Anaesthesia. 2008;63(4):352-357.

11. Salman AE, Salman MA, Saricaoglu F, Akinci SB, Aypar Ü. Pain on injection of propofol: a comparison of methylene blue and lidocaine. J Clin Anesth. 2011;23(4):270-274.

12. Sim HL, Tan KY. Randomized single-blind clinical trial of intradermal methylene blue on pain reduction after open diathermy haemorrhoidectomy. Colorectal Dis. 2014;16(8):O283-O287.

13. Tan KY, Seow-Choen F. Methylene blue injection reduces pain after lateral anal sphincterotomy. Tech Coloproctol. 2007;11(1):68-69.

14. Dudhgaonkar SP, Tandan SK, Kumar D, Naik AK, Raviprakash V. Ameliorative effect of combined administration of inducible nitric oxide synthase inhibitor with cyclooxygenase- 2 inhibitors in neuropathic pain in rats. Eur J Pain. 2007;11(5):528-534.

15. Wiklund L, Basu S, Miclescu A, Wiklund P, Ronquist G, Sharma HS. Neuro- and cardioprotective effects of blockade of nitric oxide action by administration of methylene blue. Ann N Y Acad Sci. 2007;1122: 231-244.

16. Rojas JC, Bruchey AK, Gonzalez-Lima F. Neurometabolic mechanisms for memory enhancement and neuroprotection of methylene blue. Prog Neurobiol. 2012;96(1):32-45.

17. Patil CS, Padi SV, Singh VP, Kulkarni SK. Sildenafil induces hyperalgesia via activation of the NO-cGMP pathway in the rat neuropathic pain model. Inflammopharmacology. 2006;14(1-2):22-27.
18. Abacioğlu N, Tunçtan B, Akbulut E, Cakici I. Participation of the components of L-arginine/nitric oxide/cGMP cascade by chemicallyinduced abdominal constriction in the mouse. Life Sci. 2000;67(10): 1127-1137.

19. Smith BH, Torrance N, Ferguson JA, Bennett MI, Serpell MG, Dunn KM. Towards a definition of refractory neuropathic pain for epidemiological research. An international Delphi survey of experts. BMC Neurol. 2012;12:29.

20. Cruccu G, Anand P, Attal N, et al. EFNS guidelines on neuropathic pain assessment. Eur J Neurol. 2004;11(3):153-162.

21. Cruccu G, Sommer C, Anand P, et al. EFNS guidelines on neuropathic pain assessment: revised 2009. Eur J Neurol. 2010;17(8):1010-1018.

22. Basu S. Radioimmunoassay of 8-iso-prostaglandin F2alpha: an index for oxidative injury via free radial catalysed lipid peroxidation. Prostaglandins Leukot Essent Fatty Acids. 1998;58(4):319-325.

23. Gullberg M, Gústafsdóttir SM, Schallmeiner E, et al. Cytokine detection by antibody-based proximity ligation. Proc Natl Acad Sci U S A. 2004; 101(22):8420-8424.

24. Fredriksson S, Gullberg M, Jarvius J, et al. Protein detection using proximity-dependent DNA ligation assays. Nat Biotechnol. 2002;20(5):473-477.

25. Assarsson E, Lundberg M, Holmquist G, et al. Homogenous 96-plex PEA immunoassay exhibiting high sensitivity, specificity, and excellent scalability. PLoS One. 2014;9(4):e95192.

26. Schmidtko A, Tegeder I, Geisslinger G. No NO, no pain? The role of nitric oxide and cGMP in spinal pain processing. Trends Neurosci. 2009;32(6):339-346.

27. Peter C, Hongwan D, Küpfer A, Lauterburg BH. Pharmacokinetics and organ distribution of intravenous and oral methylene blue. Eur J Clin Pharmacol. 2000;56(3):247-250.

28. Harvey BH, Duvenhage I, Viljoen F, et al. Role of monoamine oxidase, nitric oxide synthase and regional brain monoamines in the antidepressant-like effects of methylene blue and selected structural analogues. Biochem Pharmacol. 2010;80(10):1580-1591.

29. Naylor GJ, Smith AH, Connelly P. A controlled trial of methylene blue in severe depressive illness. Biol Psychiatry. 1987;22(5):657-659.

30. Arakawa A, Kaneko M, Narukawa M. An investigation of factors contributing to higher levels of placebo response in clinical trials in neuropathic pain: a systematic review and meta-analysis. Clin Drug Investig. 2015;35(2):67-81.

31. Baron R, Binder A, Wasner G. Neuropathic pain: diagnosis, pathophysiological mechanisms, and treatment. Lancet Neurol. 2010;9(8): 807-819.

32. Hao JX, Xu XJ. Treatment of a chronic allodynia-like response in spinally injured rats: effects of systematically administered nitric oxide synthase inhibitors. Pain. 1996;66(2-3):313-319.

33. Ramesh G, MacLean AG, Philipp MT. Cytokines and chemokines at the crossroads of neuroinflammation, neurodegeneration, and neuropathic pain. Mediators Inflamm. 2013;2013:480739.

34. Austin PJ, Moalem-Taylor G. The neuro-immune balance in neuropathic pain: involvement of inflammatory immune cells, immune-like glial cells and cytokines. J Neuroimmunol. 2010;229(1-2):26-50.

35. Nedvídková J, Pacák K, Haluzík M, Nedvídek J. The regulation of adenohypophyseal prolactin secretion: effect of triiodothyronine and methylene blue on estrogenized rat adenohypophysis. Physiol Res. 2000;49 Suppl 1:S27-S35.

36. Trajanovska AS, Vujovic V, Ignjatova L, Janicevic-Ivanovska D, Cibisev A. Sexual dysfunction as a side effect of hyperprolactinemia in methadone maintenance therapy. Med Arch. 2013;67(1):48-50.

37. Devilla L, Pende A, Morgano A, Giusti M, Musso NR, Lotti G. Morphine-induced TSH release in normal and hypothyroid subjects. Neuroendocrinology. 1985;40(4):303-308.

38. Vuong C, Van Uum SH, O’Dell LE, Lutfy K, Friedman TC. The effects of opioids and opioids analogs on animal and human endocrine systems. Endocr Rev. 2010;31(1):98-132.

39. Wehrenberg WB, McNicol D, Wardlaw SL, Frantz AG, Ferin M. Dopaminergic and serotonergic involvement in opiate-induced prolactin release in monkeys. Endocrinology. 1981;109(2):544-547. 
40. Schreiber V, Nedvídková J, Jahodová J. Anterior pituitary weight, cAMP, cGMP and prolactin levels after combined treatment with estradiol and methylene blue. Physiol Res. 1993;42(6):171-174.

41. Nedvídková J, Pacák K, Haluzík M, Nedvídek J, Schreiber V. The role of dopamine in methylene blue-mediated inhibition of estradiol benzoate-induced anterior pituitary hyperplasia in rats. Neurosci Lett. 2001;304(3):194-198.

42. Diogenes A, Patwardhan AM, Jeske NA, et al. Prolactin modulates TRPV1 in female rat trigeminal sensory neurons. J Neurosci. 2006; 26(31):8126-8136.

43. Calabrese EJ, Bachmann KA, Bailer AJ, et al. Biological stress response terminology: Integrating the concepts of adaptive response and preconditioning stress within a hormetic dose-response framework. Toxicol Appl Pharmacol. 2007;222(1):122-128.

44. Miclescu A, Basu S, Wiklund L. Cardio-cerebral and metabolic effects of methylene blue in hypertonic sodium lactate during experimental cardiopulmonary resuscitation. Resuscitation. 2007;75(1):88-97.

45. Evora PR, Ribeiro PJ, de Andrade JC. Methylene blue administration in SIRS after cardiac operations. Ann Thorac Surg. 1997;63(4): 1212-1213.
46. Clifton J 2nd, Leikin JB. Methylene blue. Am J Ther. 2003;10(4) 289-291.

47. Levin RL, Degrange MA, Bruno GF, et al. Methylene blue reduces mortality and morbidity in vasoplegic patients after cardiac surgery. Ann Thorac Surg. 2004;77(2):496-499.

48. Mathew S, Linhartova L, Raghuraman G. Hyperpyrexia and prolonged postoperative disorientation following methylene blue infusion during parathyroidectomy. Anaesthesia. 2006;61(6):580-583.

49. Miclescu A, Basu S, Wiklund L. Methylene blue added to a hypertonichyperoncotic solution increases short-term survival in experimental cardiac arrest. Crit Care Med. 2006;34(11):2806-2813.

50. Donati A, Conti G, Loggi S, et al. Does methylene blue administration to septic shock patients affect vascular permeability and blood volume? Crit Care Med. 2002;30(10):2271-2277.

51. Evora PR, Oliveira Neto AM, Duarte NM, Vicente WV. Methylene blue as treatment for contrast medium-induced anaphylaxis. J Postgrad Med. 2002;48(4):327.
Journal of Pain Research

\section{Publish your work in this journal}

The Journal of Pain Research is an international, peer-reviewed, open access, online journal that welcomes laboratory and clinical findings in the fields of pain research and the prevention and management of pain. Original research, reviews, symposium reports, hypothesis formation and commentaries are all considered for publication.

\section{Dovepress}

The manuscript management system is completely online and includes a very quick and fair peer-review system, which is all easy to use. Visit http://www.dovepress.com/testimonials.php to read real quotes from published authors. 